\title{
Separation of $\gamma$-Globulins from Porcine Plasma by Reversed Micellar Extraction
}

\author{
TANG HUANG YANG, ${ }^{1}$ MEI GANG YET, ${ }^{3}$ CHENG KUANG HSU, ${ }^{2}$ \\ AND BEEN HUANG CHIANG ${ }^{1 *}$
}

\author{
The Institute of Food Science and Technology, National Taiwan University, 59, Lane 144, Keelung Road, \\ Scetion 4, Taipei, ${ }^{1}$ The Food Industry Research and Development Institute, Shin-Zu, ${ }^{2}$ \\ and The Development Center for Biotechnology, Taipei, ${ }^{3}$ Taiwan, ROC
}

Received 12 March 2001/Accepted 28 May 2001

\begin{abstract}
Factors affecting the separation of $\gamma$-globulins from porcine plasma using reversed micelles were screened based on a fractional factorial design. The optimal processing conditions for obtaining the maximum yield of $\gamma$-globulins under various constraints of product purity were determined using response surface methodology (RSM) and nonlinear programming. Results showed that the $\mathrm{pH}$ and sodium chloride concentration of the aqueous phase, and the concentration of surfactant (bis-(2-ethylhexyl) sulfosuccinate sodium salt, AOT) of the organic phase were the most important factors affecting the extraction performance. An eighty-five percent product purity and ninety-seven percent yield were obtained under the extraction conditions of $400 \mathrm{mM}$ $\mathrm{NaCl}, 350 \mathrm{mM}$ AOT, and pH 7.0. The extract exhibited immunological reactivity against anti-pig IgG.
\end{abstract}

[Key words: reversed micelles, $\gamma$-globulins, porcine plasma, separation]

Pigs are an important protein source in many countries, and more than 6 million pigs are slaughtered each year to provide meat in Taiwan alone. Porcine blood is rich in proteins but is usually discarded which may cause environmental contamination. Recovering porcine blood and converting it to highly valued economic products are highly desired.

Porcine plasma is a potential source of a wide range of therapeutic proteins of benefit to patients and diseased animals. These proteins include the clotting factors VIII and IX for the treatment of hemophilia A and B, respectively; albumin used in solutions for plasma volume expansion following major fluid loss, such as that incurred after serious burns; and the immunoglobulins used in preparations for prophylaxis and treatment of at-risk individuals, particularly those with natural or induced immunodeficiency. The immunoglobulins may also be used as immunologic supplements added to food products and infant formulas (1).

The normal concentration of immunoglobulins (IgG IgA, and $\operatorname{IgM}$ ) in plasma ranges from 8-20 $\mathrm{g} / \mathrm{l}$. The immunoglobulins can be separated by ammonium or sodium sulfate precipitation (2). The most common technique used to isolate $\gamma$-globulins from human plasma for clinical use is precipitation from cold-ethanol/water mixtures according to the method of Cohn et al. (3). Other methods, such as polyethylene glycol precipitation (4), ion-exchange chromatography (US patent no. 4296027), and the chromatographic adsorption procedures using hydroxyapatite columns (5) and ferric oxide-agarose columns (6) have also been used. These methods, however, require batch operation, and are

* Corresponding author. e-mail: bhchiang@ccms.ntu.edu.tw phone: $+886-2-23632821$ fax: $+886-2-23620849$ usually time - consuming to achieve the desired purity.

Reversed micelles are aggregates of amphiphilic molecules in an organic solvent. The aqueous inner core of the reversed micelles, formed by the clustering of the polar heads of surfactant molecules, can solubilize protein molecules via electrostatic interaction, thus effecting separation. Reversed micellar extraction is an attractive separation method for large-scale operation because the process could be carried out using existing liquid-liquid extraction systems in the chemical and biochemical industries. Many protein molecules have been extracted from various solutions by reversed micelles, such as immunoglobulin $G(7)$, extracellar alkaline protease (8), ribonuclease-A, cytochrome-c, lysozme $(9,10), \alpha$-chymotrypsin, alcohol dehydrogenase (11), and $\alpha$-amylase $(12,13)$.

Factors affecting the performance of the reversed micellar system include the nature and concentration of the target protein, the $\mathrm{pH}$ and ionic strength of the aqueous phase, the extraction temperature, the type and concentration of the surfactant, and the processing time $(9,12,13)$. To study the effects of these processing parameters on the efficacy of extraction, rather tedious experimental work is often needed. To avoid the complexities of the empirical determination of optimum conditions, an appropriate design is required. In this study, a fractional factorial design was used to screen factors having a dominant effect on the process performance (14). Then, the response surface methodology was used to develop mathematical functions describing the relationships between these predominant factors and both the purity and yield of $\gamma$-globulins during extraction (15). Once the mathematical functions were established, linear and nonlinear programming techniques could be used to search for an 
optimum condition for a performance index (16-19). Our aim was to determine the processing conditions of reversed micellar extraction which could generate the highest yield of $\gamma$-globulins from porcine plasma under various levels of purity.

\section{MATERIALS AND METHODS}

Reagents Bovine albumin, rabbit anti-pig $\gamma$-globulins, pig $\gamma$-globulins, pig fibrinogen, agarose (low electroendoosmosis), and Brilliant Blue $\mathbf{R}$ were purchased from Sigma Chemical Co. (St. Louis, MO, USA). Bis-(2-ethylhexyl) sodium sulfosuccinate (AOT; Fluka AG Chemische Fabrik, Buchs, Switzerland) was used as a surfactant for forming reversed micelles. Isooctane was purchased from Fisher Scientific Co. (New Jersey, USA) and barbital and sodium barbital were obtained from Wako Pure Chemicals (Tokyo). All other chemicals and reagents were of analytical grade or higher purity.

Raw materials Fresh porcine blood was obtained from a slaughterhouse in Taipei, Taiwan, under hygienic conditions and sodium citrate was added to a final concentration of $0.1 \%$ as an anticoagulant. The plasma, after separation from the blood cells by centrifugation, was frozen at $-20^{\circ} \mathrm{C}$ for storage. The plasma was thawed at $4^{\circ} \mathrm{C}$ and centrifuged at $3600 \times g$ for $15 \mathrm{~min}$ to collect Factor VIII procoagulant and fibrinogen. The resulting plasma was fractionated by cold precipitation and alcohol fractionation at various pHs (3), and the fraction II+ III was obtained by precipitation with $25 \%$ ethanol at $\mathrm{pH} 6.9$ and $-5^{\circ} \mathrm{C}$. The precipitate was freeze-dried and further fractionated by reversed micellar extraction.

Reversed micellar extraction Aqueous solutions were prepared by dissolving various amounts of the freeze-dried precipitate $\mathrm{II}+\mathrm{III}$ in sodium phosphate buffer of various $\mathrm{pHs}$ and concentrations. Sodium chloride was also added to the aqueous solutions to adjust the ionic strength. Organic solutions were prepared by dissolving designated amounts of AOT in isooctane.

Reversed micellar extraction usually consists of two steps. The forward extraction step involves solubilizing the target protein molecule in the aqueous inner core of the reversed micelles dispersed in the organic solution. The backward extraction step involves releasing the target protein molecule from the protein-laden micellar solution to the aqueous phase to obtain a purified protein product. However, the results of our preliminary studies revealed that it would be more feasible and economical to extract all of the non- $\gamma$-globulin components into the reversed micelles and leave the $\gamma$-globulins in the aqueous phase. Therefore, the reversed micellar extraction in this study consisted of only one step, i.e., the forward extraction step, in which equal volumes (ca. $4 \mathrm{ml}$ ) of the organic and aqueous solutions were mixed in a centrifugal tube $(15 \mathrm{ml})$ at ca. $200 \mathrm{rpm}$ in a reciprocating shaker bath for various timc periods. The resulting mixture was then centrifuged at $1000 \times g$ for $10 \mathrm{~min}$ to separate the two phases. Samples of the aqueous phase were then taken for analyses.

The experimental design Seven experimental factors were initially considered that might affect the purity and yield of the $\gamma$ globulins. To reduce the number of experimental variables to a level which could be handled practically, a $2^{7-3}$ fractional factorial design was used to screen the critical factors among the seven factors. The experimental design selected a one-eighth replication of a factorial design for seven experimental variables each having two treatment levels. Table 1 shows the coded and actual levels of the experimental variables. After representing the purity and yield as linear functions of the coded levels of the seven experimental variables using multilinear regression techniques, the relative magnitude of the regression coefficients associated with the experi- mental variables allowed us to determine the critical variables.

The effects of the selected critical factors on the purity and yield of the $\gamma$-globulins were further determined experimentally based on a Box-Behnken design (15) (experiments no. 1-13 in Table 2). All experimental runs were performed in random order. Therefore, mathematical functions giving the purity and yield as a function of the selected critical variables could be developed. However, one of the drawbacks of using the Box-Behnken design for building mathematical models is that poor estimations may result in the response values at the extremes, that is, at the points at which all variables are either at their highest or lowest levels. To overcome this problem, 8 extreme points were then added to increase the estimation power close to the extremes (experiment no. 14-21 in Table 2).

Model building and data analysis $A$ stepwise regression procedure in the SAS package (SAS Institute Inc., Cary, NC, USA) was used to fit the purity and yield data into second order polynomial equations with interaction terms:

$$
Y=B_{\mathrm{o}}+B_{\mathrm{i}} \Sigma X_{\mathrm{i}}+B_{\mathrm{ij}} \Sigma X_{\mathrm{i}}^{2}+B_{\mathrm{ij}} \sum X_{\mathrm{i}} X_{\mathrm{j}} \quad(i \neq j)
$$

where $Y$ is the dependent variable (percentage), $B_{0}, B_{\mathrm{i}}, B_{\mathrm{ij}}, B_{\mathrm{ij}}$ are regression coefficients of the model, and $X_{\mathrm{i}}$ are magnitudes of the selected critical variables. An $F$ test for lack of fit was used to determine whether the regression models adequately fit the experimental data. Once the regression models were developed, 7 new experimental points selected randomly were conducted to test the models.

Nonlinear programming Once the regression functions were developed, nonlinear programming techniques were used to determine the maximum yield of $\gamma$-globulins under various levels of purity. A commercial linear and nonlinear programming package "AMPL" (The Scientific Press, San Francisco, CA, USA) $(17,18)$ was used to determine the optimal conditions. For solving a nonlinear equation with nonlinear constraint functions, the equations were transformed with the augmented Lagrangian procedures described by Robinson (19) and Murtagh and Saunders (18), into a sequence of linearly constrained subproblems which could be solved using a reduced gradient algorithm (16).

Analytical methods The protein concentration was determined by the Lowry method using the Bio-Rad DC protein assay kit (BioRad Lab. CA, USA). Quantitation of fibrinogen was carried out using a fibrinogen assay kit (Helena Lab., TX, USA). SDS-polyacrylamide gel electrophoresis was performed and gels were stained by Coomassie Brilliant Blue. Agarose-cellulose acetate sheets, Titan gels, were purchased from Helena Lab. and electrophoresis was carried out at 80 volts for $35 \mathrm{~min}$ at $25^{\circ} \mathrm{C}$. The sheets were dried in a drier at $60^{\circ} \mathrm{C}$ for $30 \mathrm{~min}$ and stained with $0.2 \%$ Coommassie Blue $\mathrm{R}$ in methanol/water/acetic acid $(5 / 5 / 1$, $\mathrm{v} / \mathrm{v} / \mathrm{v}$ ) for $10 \mathrm{~min}$. The sheets were destained with a destaining solution (acetic acid/methanol/water, 1/3/6, v/v/v) and scanned with a densitometer (model SLR-1D/2D, Biomed Instruments Inc., CA, USA) at $595 \mathrm{~nm}$ for quantitation of albumin, $\alpha-, \beta$-, and $\gamma-$ globulins. The purity of the $\gamma$-globulins was calculated as the percentage of their peak areas against the total peak area of the sample. The yield of $\gamma$-globulins was estimated by dividing the amount of $\gamma$-globulins in the aqueous phase after extraction by the total amount of $\gamma$-globulins in Cohn's fraction II + III. The amount of $\gamma$-globulins in the sample was calculated by multiplying the purity of the $\gamma$-globulins in the sample by the protein concentration of the sample.

Activity assay Double gel diffusion was performed on a glass slide. The slide was precoated with $0.5 \%$ agarose and overlayered with $2 \%$ agarose in $0.015 \mathrm{M}$ barbitone buffer, $\mathrm{pH} 8.2$. The central well was filled with $4 \mu \mathrm{l}$ of rabbit anti-pig IgG $2 \mathrm{mg} / \mathrm{ml}$, and the peripherial wells were filled with the purified porcine $\gamma$-globulins. The precipitation reaction was carried out at $37^{\circ} \mathrm{C}$ for $12 \mathrm{~h}$. 


\section{RESULTS AND DISCUSSION}

Preparation of crude $\gamma$-globulins The high molecular weight proteins, such as Factor VIII and fibrinogen, were concentrated in the precipitate after thawing of the frozen plasma at $4^{\circ} \mathrm{C}$. The remaining plasma proteins were fractionated by Cohn's method to obtain the fraction I precipitate using $8 \%$ alcohol, $\mathrm{pH} 7.2$, at $-3^{\circ} \mathrm{C}$. Most of the remaining fibrinogen and other high MW proteins were precipitated in this fraction. Cohn's fraction II+ III was then obtained by precipitation in $25 \%$ alcohol, $\mathrm{pH} 6.9$, at $-5^{\circ} \mathrm{C}$. The protein components in fraction II+III were analyzed by agarose-acetate electrophoresis (Fig. 3) and the stained gels were scanned by densitometry to quantitate the relative abundance of albumin $(13.7 \%), \alpha-(12.8 \%), \beta-(7.8 \%)$, and $\gamma$-globulins $(65.7 \%)$ and fibrinogen (non-detectable). The high enrichment of $\gamma$-globulins in this fraction is significantly different from previous observations on human Cohn's fraction II+III, which was found to contain albumin $(4 \%), \alpha-(6 \%), \beta-(48 \%), \gamma$-globulins (37\%) and fibrinogen $(5 \%)$. This data may reflect xenogenic differences in plasma composition, for example, differences in the molecular sizes and charges of $\beta$-globulins may affect precipitation of the globulins by cold alcohol at various pHs. The immunological exposure of pigs during their life span may also contribute to the absolute amount of immunoglobulins in plasma.

Processing parameters screening The aim of this part of the study was to identify the processing variables that had a decisive effect on the extraction performance, namely, the yield and purity of the $\gamma$-globulins. Seven variables were investigated using the fractional factorial design, and the results are given in Table 1. Based on the experimental data, two linear regression models for the purity $\left(Y_{1}\right)$ and yield $\left(Y_{2}\right)$ of $\gamma$-globulins were obtained:

$$
\begin{aligned}
Y_{1}= & 40.106+1.681 x_{1}-3.806 x_{2}+13.719 x_{3}+2.019 x_{4} \\
& +6.831 x_{5}-0.819 x_{6}+5.119 x_{7} \\
Y_{2}= & 43.125+28.975 x_{1}+2.375 x_{2}+9.050 x_{3}-3.363 x_{4} \\
& +3.650 x_{5}-1.579 x_{6}+8.713 x_{7}
\end{aligned}
$$

In general, the magnitude of the coefficients of the linear regression models could be used to judge the extent of the contribution of the corresponding independent variables to the dependent variables. The phosphate in the aqueous phase was used to adjust the $\mathrm{pH}$ and to provide the appropriate ionic strength for the extraction. The negative value of the regression coefficient for phosphate concentration $\left(x_{2}\right)$ in equation (1) indicated that the purity of $\gamma$-globulins decreased as the phosphate concentration increased. On the other hand, increasing the phosphate concentration increased the yield of $\gamma$-globulins (Eq. 2). Apparently, a high phosphate concentration in the aqueous phase prevented all of the protein components, including the $\gamma$-globulins, in the porcine plasma from being solubilized into the reversed micelles. Since the ionic strength of the aqueous phase was adjusted primarily by sodium chloride the phosphate concentration was fixed at $50 \mathrm{mM}$, the median value determined in the screening test, for subsequent experiments. Theoretically, the effect of protein concentration in the aqueous phase on the extraction performance should be correlated to the surfactant concentration in the organic phase. A higher protein concentration would require more surfactant in the organic solution to form micelles to accomplish the protein solubilization. Because the AOT concentration was going to be subjected to further study, adjusting the protein concentration appeared to be unnecessary. Therefore, the protein concentration was fixed at $10 \mathrm{mg} / \mathrm{ml}$. According to the regression coefficients of Eqs. 1 and 2, the extraction time had the least influence on the process performance among the seven processing factors. Too long an extraction time

TABLE 1. The purity and yield of the $\gamma$-globulins based on a $2^{7-3}$ fractional factorial design

\begin{tabular}{rrrrrrrrrr}
\hline No. & $x_{1}$ & $x_{2}$ & $x_{3}$ & $x_{4}$ & $x_{5}$ & $x_{6}$ & $x_{7}$ & Purity & Yield \\
\hline 1 & -1 & -1 & -1 & -1 & -1 & -1 & -1 & 2.8 & 0.1 \\
2 & -1 & -1 & -1 & +1 & -1 & +1 & +1 & 9.7 & 3.5 \\
3 & -1 & -1 & +1 & -1 & +1 & +1 & +1 & 81.9 & 50.6 \\
4 & -1 & -1 & +1 & +1 & +1 & -1 & -1 & 81.9 & 25.8 \\
5 & -1 & +1 & -1 & -1 & +1 & -1 & +1 & 8.8 & 0.5 \\
6 & -1 & +1 & -1 & +1 & +1 & +1 & -1 & 19.0 & 7.3 \\
7 & -1 & +1 & +1 & -1 & -1 & +1 & -1 & 14.8 & 1.0 \\
8 & -1 & +1 & +1 & +1 & -1 & -1 & +1 & 88.5 & 24.4 \\
9 & +1 & -1 & -1 & -1 & +1 & +1 & -1 & 62.2 & 37.0 \\
10 & +1 & -1 & -1 & +1 & +1 & -1 & +1 & 35.5 & 73.2 \\
11 & +1 & -1 & +1 & -1 & -1 & -1 & +1 & 44.0 & 82.7 \\
12 & +1 & -1 & +1 & +1 & -1 & +1 & -1 & 33.3 & 53.1 \\
13 & +1 & +1 & -1 & -1 & -1 & +1 & +1 & 48.7 & 100 \\
14 & +1 & +1 & -1 & +1 & -1 & -1 & -1 & 24.4 & 51.0 \\
15 & +1 & +1 & +1 & -1 & +1 & -1 & -1 & 41.5 & 100 \\
16 & +1 & +1 & +1 & +1 & +1 & +1 & +1 & 44.7 \\
\hline
\end{tabular}

The actual levels corresponding to the coded levels of each variable:

$x_{1}: \mathrm{pH}$ of aqueous phase: $-1: 4.8 \quad 1: 7.9$

$x_{2}$ : phosphate concentration in aqueous phase: $-1: 201: 100 \mathrm{mM}$.

$x_{3}: \mathrm{NaCl}$ concentration in aqueous phase: $-1: 501: 200 \mathrm{mM}$.

$x_{4}$ : protein concentration in aqueous phase: $-1: 51: 15 \mathrm{mg} / \mathrm{ml}$.

$x_{5}$ : AOT concentration in organic phase: $-1: 501: 100 \mathrm{mM}$.

$x_{6}$ : process time: $-1: 1 \quad 1: 2 \mathrm{~h}$.

$x_{7}$ : process temperature: $-1: 51: 25^{\circ} \mathrm{C}$. 
(e.g., $2 \mathrm{~h}$ ) might have increased the chance of the proteins coming in contact with the organic solvent, leading to protein denaturation thus affecting the extraction. Therefore, the extraction time was fixed at $1 \mathrm{~h}$. Increasing the extraction temperature increased both the purity and yield of the $\gamma$-globulins. However, too high a temperature may also damage the activity of the $\gamma$-globulins. Considering both process performance and operational convenience, the extractions were carried out at room temperature $\left(25^{\circ} \mathrm{C}\right)$ for subsequent investigations. Consequently, three variables, the $\mathrm{pH}$ of the aqueous phase $\left(x_{1}\right)$, the $\mathrm{NaCl}$ concentration $\left(x_{3}\right)$, and the AOT concentration $\left(x_{5}\right)$ were chosen as the critical factors that would be subjected to further study.

Effects of extraction conditions on yield and purity of the $\gamma$-globulins Separate experiments were conducted to determine the effects of the critical variables, $\mathrm{pH}$ of the aqueous phase $\left(X_{1}\right)$, sodium chloride concentration $\left(X_{2}\right)$ of the aqueous phase, and AOT concentration $\left(X_{3}\right)$ of the organic phase, on the purity $\left(Y_{1}\right)$ and yield $\left(Y_{2}\right)$ of the $\gamma$-globulins based on a Box-Behnken design with the addition of 8 extreme points, and the results are shown in Table 2. Two models based on stepwise regression analysis were then developed showing the purity and yield as a function of the critical processing variables:

$$
\begin{aligned}
Y_{1}= & 61.1367+10.6746 X_{1}-0.0314 X_{2}+0.0109 X_{3} \\
& -1.20447 X_{1}^{2}+0.00601 X_{1} X_{2} \\
Y_{2}= & -326.3867+98.7041 X_{1}+0.2281 X_{2}-0.202 X_{3} \\
& -6.108 X_{1}^{2}+0.00056 X_{3}^{2}-0.02044 X_{1} X_{2}
\end{aligned}
$$

The coefficient of determination $\left(\mathrm{R}^{2}\right)$ of the model for purity was 0.85 , indicating a generally good fit of the model. Even though the model for yield had a low $\mathrm{R}^{2}$ value, 0.77 , the lack of fit was not significant $(p=0.13)$ indicating the adequacy of the model. The highest possible purity of the $\gamma$-globulins resulting from reversed micellar extraction was estimated to be $88.1 \%$ using the nonlinear programming technique, which was obtained by operating the extraction at $\mathrm{pH} 5$, and at a sodium chloride concentration of $100 \mathrm{mM}$ and an AOT concentration of $350 \mathrm{mM}$. By fixing one of the three variables at the optimum for obtaining the highest purity, the effect of the other two variables on the purity and yield of the $\gamma$-globulins could be further explored, as illustrated by Figs. 1 and 2 .

When the $\mathrm{pH}$ of the aqueous solution was set at 5, the effects of the sodium chloride and AOT concentrations on the purity of the $\gamma$-globulins were interrelated (Fig. 1a). $\Lambda t$ low $\mathrm{NaCl}$ concentration, the purity increased with increasing AOT concentration. Most of the proteins in porcine plasma were positively charged at $\mathrm{pH} \mathrm{5,} \mathrm{thus,} \mathrm{AOT,} \mathrm{an} \mathrm{an-}$ ionic surfactant, extracted the proteins from the aqueous phase to the organic phase. The amount of the proteins, including the $\gamma$-globulins, extracted from the aqueous phase to the organic phase increased with increasing AOT concentration, and therefore, the purity of the $\gamma$-globulins in the aqueous phase increased. However, a high concentration of $\mathrm{NaCl}$ interfered with the electrostatic interactions between the proteins and AOT and reduced the beneficial effect of raising the AOT concentration.

When the $\mathrm{NaCl}$ concentration was $100 \mathrm{mM}$, no signifi-
TABLE 2. Effects of process variables on the purity and yield of the $\gamma$-globulins based on a Box-Behnken design

\begin{tabular}{rrrrrr}
\hline No. & $\mathrm{pH}$ & {$[\mathrm{NaCl}]$} & [AOT] & Purity (\%) & Yield (\%) \\
\hline 1 & 1 & 1 & 0 & 73.7 & 83.9 \\
2 & 1 & -1 & 0 & 63.4 & 52.1 \\
3 & -1 & 1 & 0 & 85.8 & 50.0 \\
& -1 & 1 & 0 & 80.9 & 47.6 \\
4 & -1 & -1 & 0 & 84.2 & 6.7 \\
5 & 1 & 0 & 1 & 68.5 & 81.8 \\
6 & 1 & 0 & -1 & 62.8 & 65.6 \\
& 1 & 0 & -1 & 61.3 & 53.8 \\
7 & -1 & 0 & 1 & 92.4 & 72.5 \\
8 & -1 & 0 & -1 & 93.9 & 54.7 \\
9 & 0 & 1 & 1 & 80.3 & 89.7 \\
10 & 0 & 1 & -1 & 83.1 & 98.0 \\
11 & 0 & -1 & 1 & 85.0 & 71.2 \\
12 & 0 & -1 & -1 & 74.2 & 64.0 \\
& 0 & -1 & -1 & 75.2 & 83.6 \\
13 & 0 & 0 & 0 & 84.8 & 56.0 \\
& 0 & 0 & 0 & 82.2 & 61.5 \\
& 0 & 0 & 0 & 85.5 & 70.4 \\
14 & 1 & 1 & 1 & 73.1 & 80.5 \\
15 & 1 & 1 & -1 & 69.8 & 72.7 \\
16 & 1 & -1 & 1 & 63.5 & 67.2 \\
17 & 1 & -1 & -1 & 69.8 & 69.6 \\
18 & -1 & 1 & 1 & 86.8 & 58.3 \\
19 & -1 & 1 & -1 & 83.5 & 37.5 \\
20 & -1 & -1 & 1 & 87.2 & 7.4 \\
21 & -1 & -1 & -1 & 81.3 & 10.6 \\
\hline & 1 & & &
\end{tabular}

The actual levels corresponding to the coded levels of each variable: $\mathrm{pH}$ (pH of aqueous phase): $-1: 5.0 \quad 0: 7.0 \quad 1: 9.0$

$\mathrm{NaCl}(\mathrm{NaCl}$ concentration in aqueous phase): $-1: 100 \quad 0: 250 \quad 1: 400 \mathrm{mM}$.

AOT (AOT concentration in organic phase): $-1: 50 \quad 0: 200 \quad 1: 350 \mathrm{mM}$.

cant interaction between the $\mathrm{pH}$ of the aqueous phase and the concentration of AOT in the organic phase was found (Fig. 1b). The purity of the $\gamma$-globulins in the aqueous phase increased with decreasing $\mathrm{pH}$. This was because the lower the $\mathrm{pH}$, the more positive charges were present on the proteins and the stronger the interactions between the proteins and AOT. Since the concentration of $\mathrm{NaCl}$ was too low to hinder the interactions between AOT and the proteins, the purity increased with increasing AOT concentration.

When the AOT concentration was set at $350 \mathrm{mM}$, the effect of $\mathrm{NaCl}$ on the purity depended upon the $\mathrm{pH}$ of the aqueous phase (Fig. 1c). Raising the concentration of $\mathrm{NaCl}$ at low $\mathrm{pH}$ resulted in lower purity of the $\gamma$-globulins, but the effect of $\mathrm{NaCl}$ concentration on purity was quite small at high $\mathrm{pH}$. Since the proteins in the aqueous phase tended to carry negative charges at high $\mathrm{pH}$, the extraction by the reversed micelles formed by the anionic AOT became quite inefficient, and thus, the effect of the $\mathrm{NaCl}$ concentration was also insignificant.

Figure 2a shows the effects of the concentrations of $\mathrm{NaCl}$ and AOT on the yield of the $\gamma$-globulins when the $\mathrm{pH}$ of the aqueous phase was set at 5 . The yield of the $\gamma$-globulins increased with increasing $\mathrm{NaCl}$ concentration. At high $\mathrm{NaCl}$ concentration, less $\gamma$-globulins were removed from the aqueous phase by $\mathrm{AOT}$ due to the hindering effect of $\mathrm{NaCl}$ on the extraction process. The yield of the $\gamma$-globulins decreased with increasing $\Lambda O T$ concentration because more $\gamma$ globulins were removed from the aqueous phase at higher 


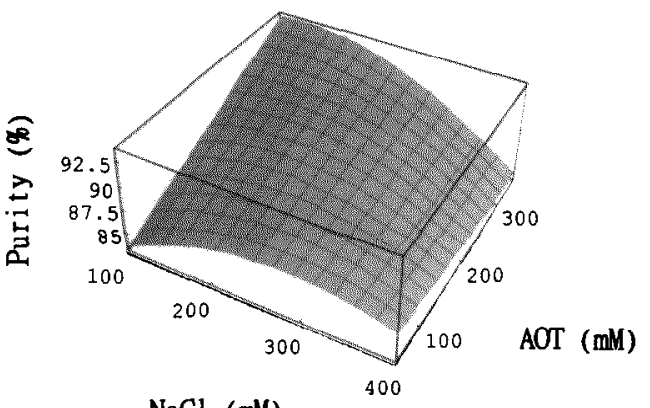

$\mathrm{NaCl}(\mathrm{mM})$

(a)

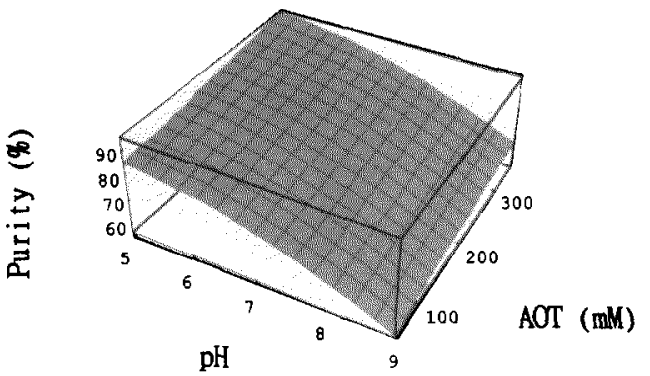

(b)

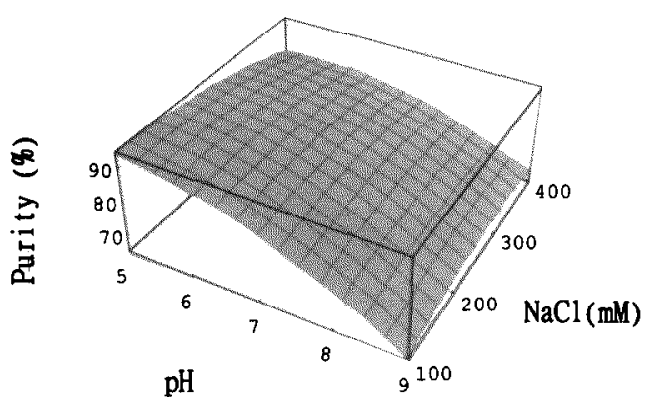

(c)

FIG. 1. Effect of process variables on the purity of the $\gamma$-globulins during reversed micellar extraction. (a) $\mathrm{pH}$ of the aqueous phase was 5; (b) sodium chloride concentration was $100 \mathrm{mM}$; (c) AOT concentration was $350 \mathrm{mM}$.

concentrations of AOT. However, when the concentration of AOT was higher than ca. $200 \mathrm{mM}$, the yield of the $\gamma$-globulins started to increase with increasing AOT concentration. It was suspected that it would be difficult to maintain a stable extraction system containing aqueous and organic phases at high AOT and $\mathrm{NaCl}$ concentrations, therefore, reducing the efficiency of the extraction process.

When the concentration of $\mathrm{NaCl}$ was set at $100 \mathrm{mM}$, the yield of the $\gamma$-globulins generally increased with increasing $\mathrm{pH}$, which was because the $\gamma$-globulins carried less positive charges at a higher $\mathrm{pH}$ resulting in less $\gamma$-globulins being transferred by the reversed micelles to the organic phase.

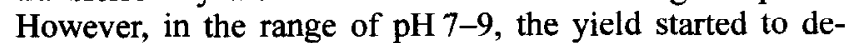
crease slightly with increasing $\mathrm{pH}$, and the reason still remains unclear.

Figure $2 \mathrm{c}$ shows the effects of $\mathrm{pH}$ and $\mathrm{NaCl}$ concentration

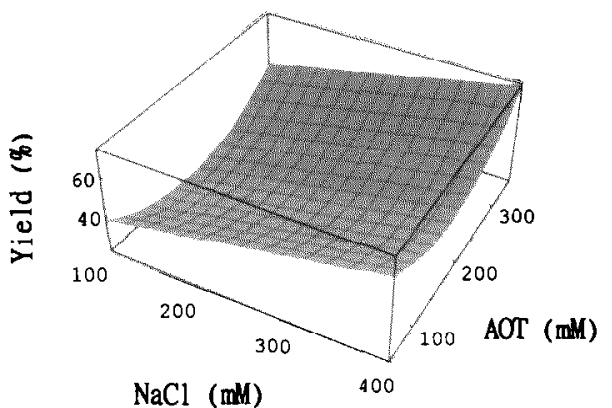

(a)

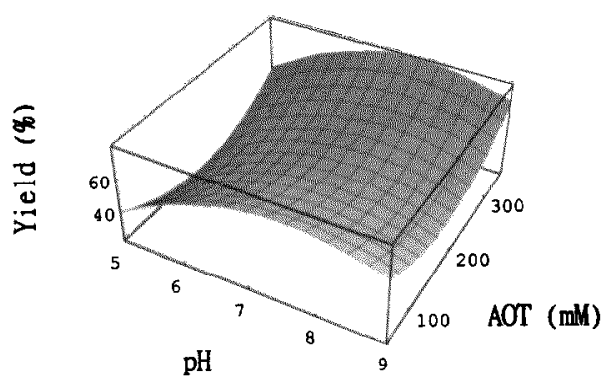

(b)

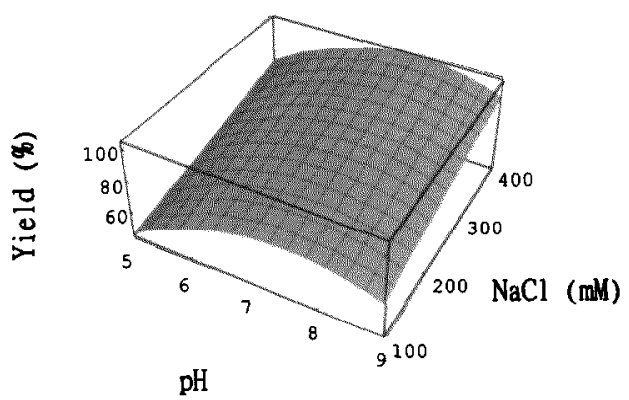

(c)

FIG. 2. Effect of process variables on the yield of the $\gamma$-globulins during reversed micellar extraction. (a) $\mathrm{pH}$ of the aqueous phase was 5; (b) sodium chloride concentration was $100 \mathrm{mM}$; (c) AOT concentration was $350 \mathrm{mM}$.

on the yield of the $\gamma$-globulins when the concentration of AOT was fixed at $350 \mathrm{mM}$. A similar trend to that described above was observed for these two extraction factors.

Efficacies of the mathematical models As stated above, the highest purity of the $\gamma$-globulins was estimated to be $88.1 \%$ if the extraction was operated at a $\mathrm{pH}$ of 5 , an $\mathrm{NaCl}$ concentration of $100 \mathrm{mM}$, and an AOT concentration of $350 \mathrm{mM}$ (Eq. 3). However, the estimated yield for the $\gamma$ globulins was only $24.9 \%$ under these extraction conditions (Eq. 4). Since only the optimum conditions resulting either in the highest purity or the highest yield could be determined, the alternative was to use the nonlinear programming technique to determine the conditions giving the optimum yield while the purity was under certain constraints, or vise versa. For example, it was estimated that a $97.0 \%$ yield 
TABLE 3. The estimated and experimental values of the purity and yield of the $\gamma$-globulins under various conditions for the reversed micellar extraction

\begin{tabular}{|c|c|c|c|c|c|c|}
\hline \multicolumn{3}{|c|}{ Extraction condition } & \multicolumn{2}{|c|}{ Purity (\%) } & \multicolumn{2}{|c|}{ Yield $(\%)$} \\
\hline $\mathrm{pH}$ & $\mathrm{NaCl}(\mathrm{mM})$ & AOT (mM) & Estimated & Actual & Estimated & Actual \\
\hline 5.0 & 100 & 350 & 88.1 & 87.4 & 24.9 & 6.0 \\
\hline 7.0 & 400 & 350 & 85.0 & 81.9 & 97.0 & 85.6 \\
\hline 8.2 & 160 & 170 & 72.4 & 71.7 & 63.8 & 65.8 \\
\hline 9.0 & 400 & 110 & 69.9 & 72.8 & 69.4 & 74.6 \\
\hline 6.6 & 280 & 290 & 84.6 & 84.9 & 73.6 & 72.6 \\
\hline 9.0 & 160 & 50 & 63.8 & 71.8 & 65.6 & 67.4 \\
\hline 8.2 & 280 & 230 & 75.2 & 72.4 & 72.4 & 58.5 \\
\hline \multicolumn{3}{|c|}{$\begin{array}{l}\text { Correlation coefficient between estimated and } \\
\text { experimental values }\end{array}$} & \multicolumn{2}{|c|}{$r=0.92$} & \multicolumn{2}{|c|}{$\mathrm{r}=0.94$} \\
\hline
\end{tabular}

of the $\gamma$-globulins could be obtained when the purity was fixed at $85 \%$. The processing conditions for these estimates are shown in Table 3. Furthermore, other extraction conditions were randomly selected, the values for both the purity and yield of the $\gamma$-globulins were estimated, and separate experiments were carried out to verify the estimated values (Table 3). It appeared that the estimated values based on the regression models were reasonably close to the experimental values. However, it was noted that under the experimental conditions of $\mathrm{pH} 5, \mathrm{NaCl} 100 \mathrm{mM}$ and AOT 350 $\mathrm{mM}$, a considerable discrepancy between the estimated yield $(24.9 \%)$ and the actual value $(6.0 \%)$ was observed. The reason for the discrepancy was that the regression model provides a poor estimation at extreme points at which all factors were either at their highest or lowest levels. In addition, errors also arose from three different sources, including random error, regression error and estimation error (or predictive error). Nevertheless, a test of lack of fit indicated the adequacy of the yield model, and the model validation using a new set of data showed a high correlation (Table 3). In addition, the correlation coefficients between the estimated values and the experimental values were 0.92 and 0.94 for purity and yield, respectively. A paired t test was also performed and the result $(p=0.195)$ did not lead us to conclude that there was a significant difference between the estimated and actual data. Therefore, the models were

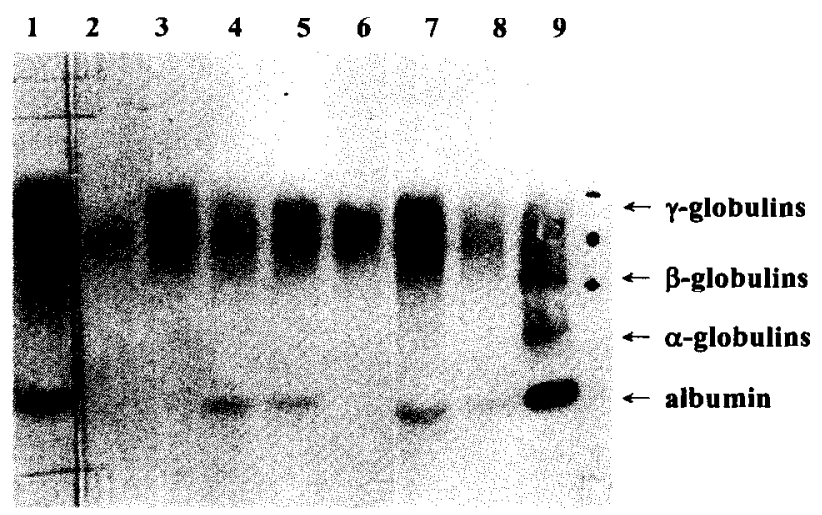

FIG. 3. Electrophoretic analysis of porcine plasma globulins. Electrophoretogram, with anode (-) on the top, is divided into albumin and globulins (alpha, beta, gamma). Sample in lane 1 is Cohn's fraction II +III; lanes 2-8 contain samples extracted under conditions specified in Table 3 starting from the first extraction condition $(\mathrm{pH} 5.0,100 \mathrm{mM}$ $\mathrm{NaCl}$ and $350 \mathrm{mM}$ AOT). Lane 9 contains porcine plasma. considered to be useful in estimating the purity and yield of the $\gamma$-globulins obtained under various extraction conditions. The electrophoretic patterns of Cohn's fraction II+III, the products from reversed micellar extraction under the conditions specified in Table 3, and the porcine plasma were compared (Fig. 3). Reversed micellar extraction removed most of the albumin and other non- $\gamma$-globulin proteins and yielded highly purified $\gamma$-globulins.

Activity assay of purified $\gamma$-globulins The $\gamma$-globulins are composed of immunoglobulins, or proteins that have immunological activity. To date, there are five classes of immunoglobulins (approximate quantity in normal human plasma, g/l): IgG (8-18), IgA (0.8-4.5), IgM (0.6-2.5), IgD (very low) and IgE (very low). The main component in porcine $\gamma$-globulins is likely to be IgG which is polyclonal due to the long-term exposure of pigs to pathogens and immunogens. It would be difficult to quantitate specific antigen-antibody reactions unless the animals have been challenged with specific known antigens. Pig IgG was used to immunize rabbits, and the antiserum (purchased from Sigma Chemical Co., P8290) was used for a double gel diffusion assay based on the principle that both reactants (antigen and antibody) move through an inert media and form a precipitin line (stable antigen-antibody complex). The characteristics of the positive immunoprecipitin lines may be interpreted in relation to a known antigen and/or antibody. In this study, two extracts were arbitrarily selected and tested, and precipitin lines werc observed (Fig. 4). These data indicated that the $\gamma$-globulins purified by reversed micellar extraction were capable of forming complexes with antiserum. A quantitative assay, such as complement fixation, antibody-dependent cytolytic activity, or antigen binding would need to be carried out in future studies.

Conclusion Reversed micellar extraction appeared to be a feasible method for separating and purifying $\gamma$-globulins from other proteins in porcine plasma. The $\mathrm{pH}$ and the concentrations of $\mathrm{NaCl}$ and surfactant (bis-(2-ethylhexyl) sulfosuccinate sodium salt, AOT) were the most important factors affecting the performance of the process. The optimum conditions were found to be $100 \mathrm{mM} \mathrm{NaCl}, 350 \mathrm{mM}$ AOT and $\mathrm{pH} 5$ with the maximum purity of $88.1 \%$. However, only a $24.9 \%$ yield was obtained under these conditions. Nevertheless, $85 \%$ purity and a $97 \%$ yield could be obtained if the processing conditions were $400 \mathrm{mM} \mathrm{NaCl}$, $350 \mathrm{mM}$ AOT, and $\mathrm{pH}$. The immunological assay indicated that the extracts still possessed immunological activi- 


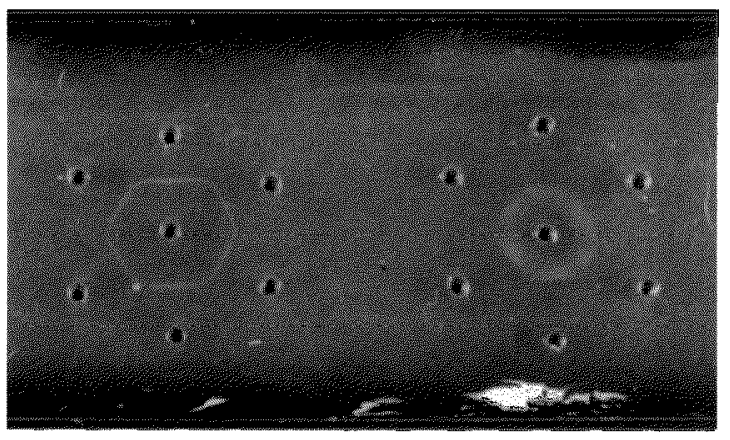

(a)

(b)

FIG. 4. Analysis of porcine $\gamma$-globulins by immunoprecipitation with rabbit anti-pig IgG. The central well was filled with rabbit antipig IgG serum, and peripheral wells with (a) sample extracted at $\mathrm{pH} 5$, an $\mathrm{NaCl}$ concentration of $100 \mathrm{mM}$ and an AOT concentration of 350 $\mathrm{mM}$ ( the first extraction condition in Table 3), and (b) the other samples extracted under various conditions as specified in Table 3. The top peripheral well contains the sample extracted at $\mathrm{pH} 7,400 \mathrm{mM} \mathrm{NaCl}$ and $350 \mathrm{mM}$ AOT (the second extraction condition in Table 3 ), and the peripheral wells following clockwise are filled with the samples extracted as outlined in Table 3 starting from the third extraction condition.

ties. However, a quantitative assay for the immunological activity of the extract is required for future studies.

\section{REFERENCES}

1. Nakai, S.: Immune factors of milk. Nutrition Quarterly, 15, 52-56 (1991).

2. Cohn, E. J., McMeekin, T. L., Oncley, J. L., Newel, J. M., and Hughes, W. L.: Preparation and properties of serum and plasma proteins. I. Size and charge of proteins separating upon equilibration across membranes with ammonium sulfate solutions of controlled $\mathrm{pH}$, ionic strength and temperature. J. Am. Chem. Soc., 62, 3386-3393 (1940).

3. Cohn, E. J., Strong, L. E., Mulford, W. L. H., Jr., Ashworthe, J. N., Melin, M., and Taylor, H. L.: Preparation and properties of serum and plasma proteins. IV. A system for the separation into fractions of the protein and lipoprotein components of biological tissucs and fluids. J. Am. Chem. Soc., 68, 459-475 (1946).

4. Polson, A. and Ruiz-Bravo, C.: Fractionation of plasma with polythylene glycol. Vox Sang., 23, 107-118 (1972).

5. Hjerten, S., Lindeberg, J., and Shopova, B.: High-performance adsorption chromatography of protein on $2-\mu \mathrm{m}$ spherical beads of hydroxyapatite. J. Chromatogr., 440, 305313 (1988).

6. Hjerten, S. and Zelikman, I.: Chromatographic purification of $\gamma$-globulins from human serum on feric oxide-agarose columns. J. Biochem. Biophys. Methods, 17, 67-74 (1988).

7. Kamihira, M., Yanagisawa, H., Takahashi, K., and Takeuchi, H.: Fractionation of IgG fragments using reversed micellar extraction. J. Ferment. Bioeng., 77, 80-84 (1994).

8. Rahaman, R. S., Chee, J. Y., Cabral, J. M. S., and Hatton, T. A.: Recovery of an extracellular alkaline protease from whole fermentation broth using reversed micelles. Biotechnol. Prog., 4, 218-224 (1988).

9. Goklen, K. E. and Hatton, T. A.: Liquid-liquid extraction of low molecular-weight proteins by selective solubilization in reversed micelles. Separation Sci. and Tech., 22, 831-841 (1987).

10. Chou, S. T. and Chiang, B. H.: Reversed micellar extraction of hen egg lysozyme. J. Food Sci., 63, 399-402 (1998).

11. Matzke, S. F., Creagh, A. L., Haynes, C. A., Prausnitz, J.M., and Blanch, H. W.: Mechanism of protein solubilization in reverse micelles. Biotechnol. Bioeng., 40, 91-102 (1992).

12. Dekker, M., Riet, K. V., and Weijers, S. R.: Enzyme recovery by liquid-liquid extraction using reversed micelles. Chemical Engineering J., 33, B27-B33 (1986).

13. Dekker, M., Riet, H., and Laane, C.: Review: isolating enzyme by reversed micelles. Anal. Biochem., 178, 217-226 (1989).

14. Cochran, W. G. and Cox, G. M.: Experimental designs, p. 244-269. John Wiley \& Sons, New York (1957).

15. Box, G. E. P. and Behnken, D. W.: Some new three level designs for the study of quantitative variables. Technometrics, 2, 455-475 (1960).

16. Wolfe, P.: Methods of nonlinear programming, p. 97-131. In Abadie, J. (ed.), Nonlinear programming. North-Holland Pub. Co., Amsterdam (1967).

17. Murtagh, B. A. and Saunders, M. A.: Large-scale linearly constrained optimization. Math. Prog., 14, 41-72 (1978).

18. Murtagh, B. A. and Saunders, M. A.: A projected Lagrangiar algorithm and its implementation for sparse nonlinear constraints. Math. Prog. Study, 16, 84-117 (1982).

19. Robinson, S. M.: A quadratically convergent algorithm for gcneral nonlincar programming problems. Math. Prog., 3, 145-156 (1972). 